\title{
Impact of hormonal treatment duration in combination with radiotherapy for locally advanced prostate cancer: Meta-analysis of randomized trials
}

Federica Cuppone ${ }^{1 \dagger}$, Emilio Bria ${ }^{1 *+}$, Diana Giannarelli², Vanja Vaccaro ${ }^{1}$, Michele Milella ${ }^{1}$, Cecilia Nisticò ${ }^{1}$, Enzo Maria Ruggeri ${ }^{3}$, Isabella Sperduti ${ }^{2}$, Sergio Bracarda ${ }^{6}$, Paola Pinnarò ${ }^{1}$, Gaetano Lanzetta ${ }^{4}$, Paola Muti ${ }^{5}$, Francesco Cognetti ${ }^{1}$, Paolo Carlini ${ }^{1}$

\begin{abstract}
Background: Hormone therapy plus radiotherapy significantly decreases recurrences and mortality of patients affected by locally advanced prostate cancer. In order to determine if difference exists according to the hormonal treatment duration, a literature-based meta-analysis was performed.

Methods: Relative risks (RR) were derived through a random-effect model. Differences in primary (biochemical failure, BF; cancer-specific survival, CSS), and secondary outcomes (overall survival, OS; local or distant recurrence, LR/DM) were explored. Absolute differences (AD) and the number needed to treat (NNT) were calculated. Heterogeneity, a meta-regression for clinic-pathological predictors and a correlation test for surrogates were conducted.

Results: Five trials (3,424 patients) were included. Patient population ranged from 267 to 1,521 patients. The longer hormonal treatment significantly improves BF (with significant heterogeneity) with an absolute benefit of $10.1 \%$, and a non significant trend in CSS. With regard to secondary end-points, the longer hormonal treatment significantly decrease both the LR and the DM with an absolute difference of $11.7 \%$ and $11.5 \%$. Any significant difference in OS was observed. None of the three identified clinico-pathological predictors (median PSA, range 9.5-20.35, Gleason score 7-10, 27-55\% patients/trial, and T3-4, 13-77\% patients/trial), did significantly affect outcomes. At the meta-regression analysis a significant correlation between the overall treatment benefit in BF, CSS, OS, LR and DM, and the length of the treatment was found ( $p \leq 0.03)$.

Conclusions: Although with significant heterogeneity (reflecting different patient' risk stratifications), a longer hormonal treatment duration significantly decreases biochemical, local and distant recurrences, with a trend for longer cancer specific survival.
\end{abstract}

\section{Background}

Androgen-deprivation remains the cornerstone of treatment for patients with hormone-sensitive advanced prostate cancer [1]. The combination of hormonal suppression and the radiotherapy is able to significantly decrease the

\footnotetext{
* Correspondence: emiliobria@yahoo.it

+ Contributed equally

'Department of Medical Oncology, Regina Elena National Cancer Institute, Roma, Italy

Full list of author information is available at the end of the article
}

recurrences and the mortality of patients affected by locally advanced prostate cancer. Substantial toxicities were also identified when hormone therapy was used. [2-11]. A recently conducted meta-analysis has demonstrated an overall absolute benefit of $7.5-10 \%$ in favor of the addition of the hormone therapy to in terms of biochemical failure and clinical progression free survival [12].

The optimal duration of androgen ablation therapy is still controversial despite a growing number of prognostic factors that have been shown to predict disease

\section{() Biomed Central}


outcome [13]. In all prospective randomized trials, long term hormonal therapy (more than 2 years) improves survival in patients with locally high risk (Gleason score $\geq 8$, median PSA $\geq 20$, stage $\geq$ T3) advanced prostate cancer. This strategy, however, is also associated with an increased risk of morbidities, such as osteoporosis, diabetes, depression, dislipidemia and abdominal obesity $[14,15]$.

The value of short-term hormonal treatment in patients with intermediate risk disease (Gleason score $\geq$ 7 , median PSA $\geq 10$, stage $\geq$ T2c) has also been detected $[16,17]$, although its role in high-risk disease is still controversial. Nevertheless, short courses of hormonal suppression have been shown to be very effective in downstaging localized disease. Surgical series have provided some histopathological confirmation, with significant decreases in margin-positive rates in prostatectomy after neoadjuvant hormonal therapy $[18,19]$.

In order to determine if difference exists between a shorter and a longer hormone therapy (HT) in combination with radiotherapy, a literature based meta-analysis was conducted.

\section{Methods}

The analysis was conducted following 4 steps: definition of the outcomes (definition of the question the analysis was designed to answer), definition of the trial selection criteria, definition of the search strategy, and a detailed description of the statistical methods used [20,21].

\section{Outcome definition}

The combination of a short-term HT (ST) and RT was considered as the experimental arm and a long-term HT (LT) and RT as the standard comparator. Analysis was conducted in order to find significant differences in primary and secondary outcomes, according to a previously published meta-analysis and the reported sequence and definitions in the selected trials. Primary outcomes for the magnitude of the benefit analysis were both the Biochemical Failure (BF, time between randomization and PSA increase) and the CSS (time between randomization and death for prostate cancer). Secondary end-points were: OS (time between randomization and death for any cause), local failure rate (LF) and distant metastases rate $(\mathrm{DM})$.

\section{Search strategy}

Deadline for trial publication and/or presentation was September $30^{\text {th }}, 2010$. Updates of Randomized Clinical Trials (RCTs) were gathered through Medline (PubMed: http://www.ncbi.nlm.nih.gov/PubMed), ASCO (American Society of Clinical Oncology, http://www.asco.org), ESMO (European Society for Medical Oncology, http:// www.esmo.org), FECS (Federation of European Cancer
Societies, http://www.fecs.be), and ASTRO (American Society for Therapeutic Radiology and Oncology, http:// www.astro.org) website searches. Key-words used for searching were: adjuvant hormone therapy, prostate cancer, radiotherapy, duration, longer, shorter, review, metanalysis, meta-analysis, pooled analysis, randomized, phase III, comprehensive review, systematic review. In addition to computer browsing, review and original papers were also scanned in the reference section to look for missing trials. Furthermore, lectures at major meetings (ASCO, ESMO, ECCO, and ASTRO) having 'hormone treatment and radiotherapy for prostate cancer' as the topic were checked. No language restrictions were applied.

\section{Trial identification criteria}

All prospective phase III RCTs published in peerreviewed journals or presented at the ASCO, ECCO, ESMO and ASTRO meetings until September 2010, in which previously untreated patients with locally advanced prostate cancer were prospectively randomized to short or long-HT plus radiotherapy were gathered. Any trial exploring a shorter versus a longer HT (regardless of their absolute values) in combination with RT for the treatment of LAPC was considered eligible.

\section{Data extraction}

The number of events for primary and secondary endpoints were extracted; the last trial's available update was considered as the original source. All data were reviewed and separately computed by five investigators (F.Cu., E.B., D.G., I.S., and P.C.).

\section{Data synthesis}

The log of relative risk ratio (RR) was estimated for each considered endpoint [22], and 95\% Confidence Intervals (CI) were derived [23]. A random-effect model according to the DerSimonian method was preferred to the fixed, given the known clinical heterogeneity of trials [24-26]; a Q-statistic heterogeneity test was used [27-29]. Absolute benefits for each outcome were calculated (i.e. absolute benefit $=\exp \{R R \times \log [$ control survival]\} - control survival [30]; modified by Parmar and Machin [31]). The number of patients needed to be treated for one single beneficial patient was determined (NNT: 1/[(Absolute Benefit)/100]) [32]. Results were depicted in all figures as conventional meta-analysis forest plots; a $R R<1.0$ indicates fewer events in the experimental arm. In order to find possible correlations between outcome effect and negative prognostic factors (selected among trials' reported factors: the median PSA, the Gleason score of 7-10 and the T3-4), a metaregression approach was adopted (i.e. regression of the selected predictor on the Log RR of the corresponding outcome); the time delay in months for each considered 
trial between the duration of the short and the long treatment arm was considered in the meta-regression analysis as treatment predictor as well. Calculations were accomplished using the Comprehensive MetaAnalysis Software, version v. 2.0 (CMA, Biostat, Englewood, NJ, USA).

\section{Correlation}

Potential correlations to test surrogacy between primary and secondary end-points, were explored according to regression between the calculated RRs and their logs for each outcome.

\section{Results}

\section{Selected trials}

Twelve trials $(7,811$ patients) were identified (Figure 1$)$ [2-11,33-37]. Seven RCTs were excluded because HT was administered in one arm only (4,387 patients) [2-11,33], question already answered in a previous metaanalysis [38]. Five RCTs were included in the metaanalysis, all evaluable for BF (3,424 patients) [7,34-37]. According to the trial' selection, the shorter approach ranged from 3 to 6 months, while the longer from 8 to 36 months; trials characteristics are listed in Table 1. Four were evaluable for CSS, OS, and three for LR and DM [34-37]. Toxicity analysis was not performed because data about toxicity were available only in two studies. Median follow-up ranged from 3.7 to 10 years. Three predictors were identified: median PSA (range 9.5-20.35), Gleason score 7-10 (range 27-55\% of patients/trial) and T3-4 (range 13-77\% patients/trial).

\section{Combined Analysis}

With regard to the primary outcomes, the longer HT significantly decreased biochemical failure over the

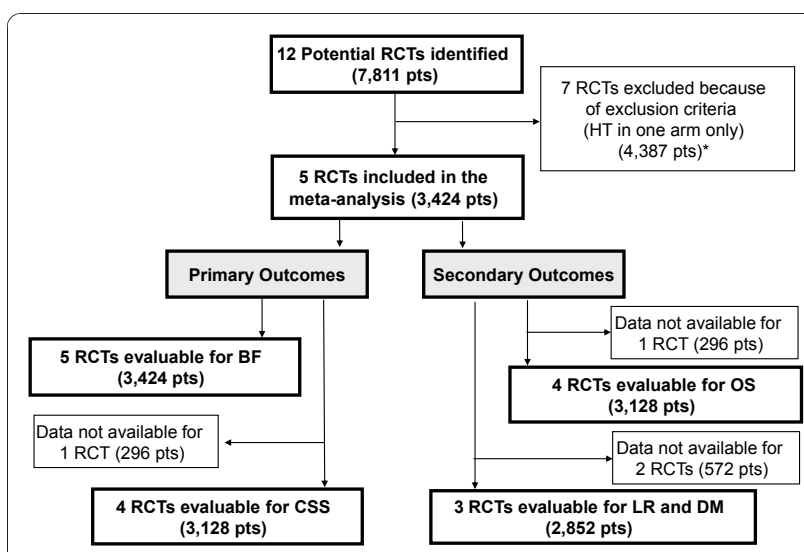

Figure 1 Outline of the search - Flow diagram. RCTs: randomized clinical trials; pts: patients; HT: hormone therapy; BF: biochemical failure; OS: overall survival; CSS: cancer specific survival; LR: local recurrences; DM: distant metastases. shorter HT with an absolute benefit of $10.1 \%$ (RR 1.32, $95 \%$ CI $1.09,1.60, \mathrm{p}=0.004)$, corresponding to $9-10$ patients to be treated for one to benefit, although with significant heterogeneity $(\mathrm{p}=0.003)$ (Table 2$)$. A non significant trend in the prostate-cancer specific survival was found ( $R R$ 1.21, 95\% CI 0.82, 1.79, p = 0.32) when adopting a longer HT, without significant heterogeneity. Concerning the secondary outcomes, the longer HT significantly reduced both the risk of local recurrences (RR $1.87,95 \%$ CI 1.22, 2.86, $\mathrm{p}=0.004$ ) and the risk of distant metastases (RR 1.77, 95\% CI 1.16, 2.69, p = 0.007) by $11.7 \%$ and $11.5 \%$, without significant heterogeneity, which translate into 9 patients to be treated for one to benefit (Table 2). No significant differences in overall survival were observed by comparing the two arms (Table 2).

According to the performed meta-regression analysis, none of the considered negative predictors significantly affected outcome. Conversely, the treatment predictor (the time delay) significantly correlates with all explored outcomes (Table 3).

\section{Correlation Analysis}

The correlation analysis was performed in the 4 RCTs, in which BF could be considered as a potential surrogate endpoint [34-36]. The regression between the RR of BF and the Log of CSS ( $p=0.005)$ was statistically significant. The regression between the RR of OS and the Log of BF and CSS was not significant $(\mathrm{p}=0.052$ and $\mathrm{p}=$ 0.16 , respectively). The regression of the RR of $D M$ and the Log of BF and CSS was statistically significant ( $\mathrm{p}=$ 0.029 and ( $p=0.041$, respectively). The regression of the RR of LR and the Log of BF was statistically significant $(\mathrm{p}=0.049)$.

\section{Discussion}

Although the number of studies is small to produce reliable estimates, the data presented herein strengthen the role of the hormone-therapy duration in patients candidates to receive androgen suppression in association with radiotherapy for locally advanced prostate cancer (Table 2 Figures 2, 3).

Hormonal suppression in patients affected by locally advanced prostate cancer candidates to receive exclusive radiotherapy is able to improve outcome, as a series of trials recently demonstrated; according to the results of our previous meta-analysis, hormonal suppression plus radiotherapy significantly decreases recurrence and mortality of patients with localized prostate cancer. The magnitude of this survival benefit ranges from $4.9 \%$ to $5.5 \%$ for OS and CSS, respectively, which translates into 20 and 18 NNT. Local and distant relapse were significantly decreased by hormonal treatment, by $36 \%$ and $28 \%$, without significantly affect toxicity [38]. 
Table 1 Trials' Characteristics

\begin{tabular}{|c|c|c|c|c|c|c|c|c|c|}
\hline \multirow[t]{2}{*}{ Authors } & \multirow[t]{2}{*}{ Pts } & \multirow[t]{2}{*}{ Dose RT (Gy) } & \multirow[t]{2}{*}{ Arms (mo.) } & \multirow{2}{*}{$\begin{array}{l}\text { Median } \\
\text { F.U. }\end{array}$} & \multicolumn{2}{|c|}{ End-Points } & \multirow{2}{*}{$\begin{array}{c}\text { Median } \\
\text { PSA (ng/mL) }\end{array}$} & \multicolumn{2}{|c|}{$\mathrm{N}^{\circ}$ of pts (\%) } \\
\hline & & & & & Primary & Secondary & & $\begin{array}{c}\text { Gleason } \\
\text { Score 7-10 }\end{array}$ & T3-T4 \\
\hline $\begin{array}{l}\text { Laverdiere } \\
\text { et al }\end{array}$ & $\begin{array}{l}148 \\
148\end{array}$ & 64 & $\begin{array}{c}5(\mathrm{AS}) \\
10(\mathrm{AS})\end{array}$ & $3.7 \mathrm{yrs}$ & BDFS, CDFS & - & $\begin{array}{l}11.9 \\
12.7\end{array}$ & $82(27.6)$ & $40(13.4)$ \\
\hline Crook et al & $\begin{array}{l}177 \\
184\end{array}$ & 66 & $\begin{array}{l}3 \text { (GF) } \\
8 \text { (GF) }\end{array}$ & 79 mo. & OS, CSS, DFS & - & $\begin{array}{c}8.9 \\
10.1\end{array}$ & $178(49.3)$ & 48 (13.2) \\
\hline $\begin{array}{l}\text { Horwitz } \\
\text { et al }\end{array}$ & $\begin{array}{l}763 \\
758 \\
\end{array}$ & $65-70$ & $\begin{array}{c}4 \text { (GF) } \\
24 \text { (GF) }\end{array}$ & $10 \mathrm{yrs}$ & DFS & OS, BF, DMF & $\begin{array}{l}20.8 \\
19.8 \\
\end{array}$ & $838(55.1)$ & $829(54.5)$ \\
\hline $\begin{array}{l}\text { Bolla } \\
\text { et al }\end{array}$ & $\begin{array}{l}483 \\
487 \\
\end{array}$ & 70 & $\begin{array}{c}6 \text { (CAB) } \\
36 \text { (CAB) }\end{array}$ & $5.2 \mathrm{yrs}$ & OS, CPFS, DS, BPFS & - & $\begin{array}{l}18.8 \\
18.8 \\
\end{array}$ & $479(49.3)$ & $754(77.7)$ \\
\hline $\begin{array}{l}\text { Armstrong } \\
\text { et al }\end{array}$ & $\begin{array}{l}127 \\
134\end{array}$ & $50-74$ & $\begin{array}{l}4 \text { (CAB) } \\
8 \text { (CAB) }\end{array}$ & $102 \mathrm{mo}$ & $\mathrm{BF}$ & OS, CSS & $\begin{array}{l}17.0 \\
13.6\end{array}$ & $153(55.4)$ & $159(57.6)$ \\
\hline
\end{tabular}

Pts: patients; RT: radiotherapy; Gy: gray; mo.: months; F.U.: follow-up; PSA: serum prostate-specific antigen; $\mathrm{N}^{\circ}$ : number; AS: androgen suppression; yrs: years; BDFS: biochemical disease free survival; CDFS: clinical disease free survival; GF: goserelin + flutamide; OS: overall survival; CSS: cancer specific survival; DFS: disease free survival; BF: biochemical failure; DMF: distant metastases failure; CAB: complete androgen blockade; CPFS: clinical progression free survival; BPFS: biochemical progression free survival: BF: biochemical failure.

Although the use of adjuvant hormonal therapy has been shown in randomized trials to improve outcomes, two issues still need to be clarified: 1) the optimal hormone therapy duration and 2) the impact of the radiation dose on outcome and local control. Within this context, the current meta-analysis was aimed to assess if difference exist between a shorter and longer androgen suppression, according to the trialist' definition. The pooled results of the considered trials show that a longer treatment approach improves all outcomes when compared to a shorter one (Table 2 Figure 2, 3). In particular, BF is significantly reduced when hormone-therapy is administered in a longer fashion, with an overall absolute difference of $10.1 \%$, which corresponds to only 9-10 patients needed to be treated for one to benefit (Table 2). Although the meta-regression analysis could be not valid given the small number of gathered trials, the benefits present across all outcomes are provided in favour of a longer strategy, regardless of any of the

Table 2 Combined efficacy results

\begin{tabular}{lcccccc}
\hline Outcomes & $\begin{array}{c}\text { Pts } \\
(\mathbf{R C T s})\end{array}$ & RR (95\% Cl) & p-value & $\begin{array}{c}\text { Het. } \\
(\boldsymbol{p})\end{array}$ & $\begin{array}{c}\text { AD } \\
(\%)\end{array}$ & NNT \\
\hline BF & $3,424(5)$ & $\begin{array}{c}1.32(1.09, \\
1.60)\end{array}$ & 0.004 & 0.003 & 10.1 & $9-10$ \\
\hline CSS & $3,128(4)$ & $\begin{array}{c}1.21(0.82, \\
1.79)\end{array}$ & 0.32 & 0.09 & - & - \\
\hline OS & $3,128(4)$ & $\begin{array}{c}1.09(0.92, \\
1.28)\end{array}$ & 0.28 & 0.15 & - & - \\
\hline DM & $2,852(3)$ & $\begin{array}{c}1.77(1.16, \\
2.69)\end{array}$ & 0.007 & 0.06 & 11.5 & 9 \\
\hline LR & $2,852(3)$ & $\begin{array}{c}1.87(1.22, \\
2.86)\end{array}$ & 0.004 & 0.10 & 11.7 & 9 \\
\hline
\end{tabular}

Pts: patients; RCTs: randomized clinical trials; RR: relative risk; Cl: confidence intervals; Het.: heterogeneity; p: p-value; AD: absolute difference; NNT: number needed to treat; BF: biochemical failure; CSS: cancer specific survival; OS: overall survival: LR: local relapse; DM: distant metastases. selected negative predictors, suggesting an overall effect independent by any clinico-pathological feature. Conversely to the these predictors, the lenght of treatment seems to significantly affect all outcomes, suggesting the even more independent value of a longer approach (Table 3). Although this interpretation should be softened, given the limitations related to a meta-regression analysis, a further individual patient data meta-analysis could eventually clarify if a particular subset of patients would better benefit of such approach. Moreover, these conclusion should be driven only when an homogenous risk classes classification was likely to be prospectively adopted in all analyzed trials. Indeed, the significant heterogeneity in the selected primary outcome can easily reflect that the magnitude of the reported benefit is different across trials, and this can likely be a clear effect of the different patient' selection.

The adopted meta-analytic method did not allow to extract patients' subgroups data from those trials where either low, intermediate and high risk patients were accrued together. For example, no advantage for longer duration was found in those trials enrolling low risk

Table 3 Meta-regression Analysis

\begin{tabular}{lcccc}
\hline Outcome & \multicolumn{4}{c}{ Predictor p-value } \\
\hline Log RR & Median PSA & G 7-10 & T3-4 & Time Delay \\
\hline BF & 0.34 & 0.35 & 0.43 & $\mathbf{0 . 0 0 0 3}$ \\
\hline CSS & 0.11 & 0.81 & 0.19 & $\mathbf{0 . 0 3}$ \\
\hline OS & 0.50 & 0.15 & 0.06 & $\mathbf{0 . 0 3}$ \\
\hline LR & 0.21 & 0.70 & 0.18 & $\mathbf{0 . 0 3}$ \\
\hline DM & 0.81 & 0.23 & 0.63 & $\mathbf{0 . 0 2}$ \\
\hline
\end{tabular}

RR: relative risk; G: Gleason score; T: t-size; Time delay: time interval between the short and the long hormonal treatment duration; BF: biochemical failure; CSS: cancer specific survival; OS: overall survival: LR: local relapse; DM: distant metastases. 


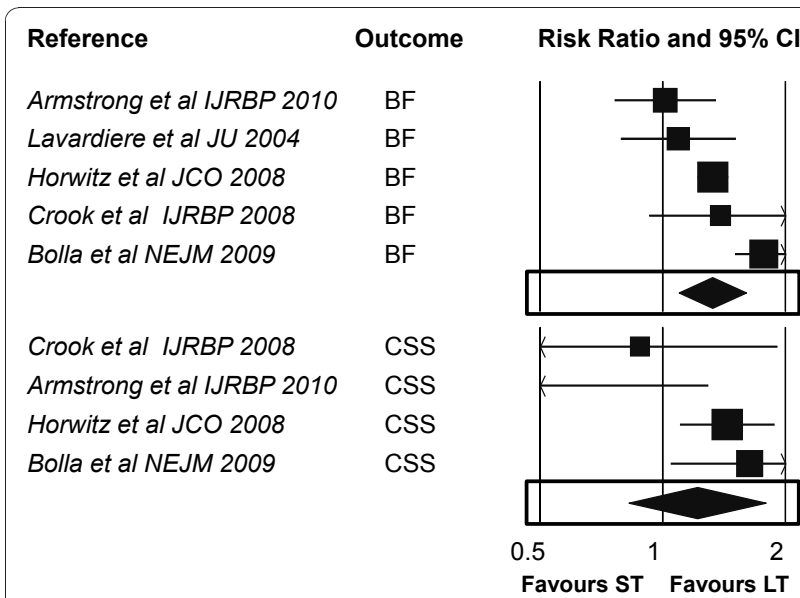

Figure 2 Combined Results - Primary Outcomes (BF, CSS). Cl: confidence intervals; BF: biochemical failure; CSS: cancer specific survival; ST: shorter therapy: LT: longer therapy.

patients [7,39] (Figure 2, 3). Conversely, the positive effect of long term hormonal duration can be partially driven by the inclusion of those 2 trials including patients with node-positive disease $[34,36]$. So, we are not able to actually exclude a 'carry-over' effect due to the inclusion of such trials with these characteristics. The mixture of such confounders (such as different cutoffs in the Gleason score) in trial selection does not allow to derive clear and definitive conclusions.

Nevertheless, even taking into account all the drawbacks in correlation and meta-regression estimations of cumulating few trials, the absolute difference in favour of the longer HT (and the lower NNT) strongly justifies a prolonged treatment strategy. Moreover, the meta-regression

\begin{tabular}{|c|c|c|}
\hline Reference & Outcome & Risk Ratio and $95 \% \mathrm{Cl}$ \\
\hline Crook et al IJRBP 2008 & os & $\longrightarrow$ \\
\hline Armstrong et al IJRBP 2010 & Os & \\
\hline Horwitz et al JCO 2008 & OS & \\
\hline Bolla et al NEJM 2009 & OS & \\
\hline Crook et al IJRBP 2008 & DM & \\
\hline Horwitz et al JCO 2008 & DM & \\
\hline Bolla et al NEJM 2009 & DM & \\
\hline Crook et al IJRBP 2008 & LR & \\
\hline Horwitz et al JCO 2008 & LR & \\
\hline \multirow[t]{2}{*}{ Bolla et al NEJM 2009} & LR & \\
\hline & & $\begin{array}{llr}0.5 & 1 & 2 \\
\text { Favours } & \text { ST } & \text { Favours }\end{array}$ \\
\hline \multicolumn{3}{|c|}{$\begin{array}{l}\text { Figure } 3 \text { Combined Results - Secondary Outcomes (OS, DM, } \\
\text { LR). Cl: confidence intervals; OS: overall survival; DM: distant } \\
\text { metastases; LR: local recurrences; ST: shorter therapy: LT: longer } \\
\text { therapy. }\end{array}$} \\
\hline
\end{tabular}

analysis did also show a significant correlation between the length of the longer strategy and the effect in the reduction of $\mathrm{BF}, \mathrm{LR}$ and $\mathrm{DM}$ and the improvement of CSS (Table 3 Figure 2). The latest conclusion allows to carefully speculate upon a 'treat-until-progression' strategy, at least in the context of a randomized trial.

Recent reports suggest that the risk of cardio metabolic problems with long-term castration deprivation therapy could counteract the benefits of hormone therapy, although this has also been questioned. Long term androgen suppression can reduce the quality of life and increase the risk of fatal myocardial infarction, fractures, and the development of a metabolic syndrome. In the context of neoadjuvant approaches, it has been recently reported that hormone-therapy is associated with a significant increase of all-cause mortality in those patients with a cardiac comorbidity, but not in those who did not show any history of cardiovascular disease [40]. This represent a crucial step-forward in the selection of those patient who could be considered as appropriate candidates for a longer hormonal suppression.

The radiotherapy component of the combined treatment is crucial: cancer-specific and overall mortality rates at 10 years are significantly lower with the combined treatment in respect to androgen suppression alone. Moreover, the survival benefit seem to depend on the duration of homone-therapy, and was also reported by the Early Prostate Cancer Programme using adjuvant antiandrogen treatment as well. In studies with short or intermediate androgen deprivation of, survival prolongation has only been reported in subgroups.

At the start of these trials, the standard radiation dose to the prostate was $70 \mathrm{~Gy}$ or less. With the advent of intensity-modulated and image-guided radiotherapy techniques, radiation doses of $78 \mathrm{~Gy}$ or higher are now possible, and randomised studies have shown that biochemical relapse-free survival improves with high radiation doses. As a consequence, the overall survival benefit might further increase further with higher safely radiation doses [41-44]. Clearly, open issues remain whether the duration of the hormonal suppression could eventually affect the outcome when radiation therapy is administered with higher dosages, and what should be irradiated (prostate or the whole pelvis).

The general shared consensus is that high risk patients would better benefit from two to three years of adjuvant androgen deprivation, while those with intermediate' risk prostate cancer from six months of adjuvant androgen deprivation plus radiotherapy delivered with a dose lower or equal to 70Gy (for doses higher than 70 Gy the appropriate duration of adjuvant androgen deprivation is still unknown) $[16,17]$. According to the trial recently published by Bolla et al, the effect of short-term and long-term androgen suppression upon five-year mortality is likely to 
be maintained at ten years $[39,45]$, whereas the short-term benefit may actually be no longer effective. The intriguing factor that can help in the daily decision between one strategy over the other is the relative weight of adverse events and the adverse effects on quality of life between the two groups of patients; indeed, although no significant difference in the overall quality of life did emerge between the two groups in the Bolla et al trial $(\mathrm{p}=0.37)$, a clinically meaningful difference was present for hot flushes, sexual interest, and sexual activity [34]. Unfortunately, our analysis could investigate neither the pooled toxicities nor the quality of life data into a cumulative fashion, given the lack of a complete reporting in the original trials.

Although the treatment duration seems to significantly impact upon outcome, it should be acknowledged that other factors may have a critical role, or may be more important: indeed, in the recent update of the Crook et al study, the more relevant weight for benefit seems related more to the early biochemical response to hormonal treatment before radiotherapy, rather than its overall duration [46]. For these reasons, a critical view of all data as shown in our analysis (taking into account all the limitations related to the adopted approach and methodology) is recommended.

\section{Conclusions}

Taking into account the current data available in literature, and the results reported herein, the significant differences in outcome in favour of a longer hormonal treatment duration do support the adoption of such a strategy for patients affected by locally advanced prostate cancer, although several limitations should be considered given the small number of trials included. Nevertheless, a careful patient selection upon the presence/absence of cardiovascular and/or metabolic comorbidities should be adopted, in order to avoid significan late-term toxicities. On the contrary, a wide adoption of a longer administration regardless of the risk stratification (notwithstanding the results of the meta-regression analysis) seems in some way not enough mature, in absence of more reliable data coming from an individual patient data meta-analysis.

\section{Authors' contributions section}

$\mathrm{FCu}, \mathrm{EB}, \mathrm{DG}$, and $\mathrm{PC}$ conceived the analysis, and supervised the calculations; FCu, EB, DG, IS, and PC performed the calculations in a blinded fashion; VV, MM, EMR, IS, and PC participated in the trials recruitment and selection process; FCu, EB, SB and PC drafted and revised the manuscript; DG, CN, PP, GL, PM, FC and PC did coordinate the overall study process and did provide the funding. All authors read and approved the final manuscript.

\section{Acknowledgements}

Supported by a grant of the National Ministry of Health and the Italian Association for Cancer Research (AIRC).

Previous Presentation:

Presented at the $45^{\text {th }}$ ASCO (American Society of Medical Oncology) annual meeting, Orlando, Florida (US), May $29^{\text {th }}$ - June $2^{\text {nd }}, 2009$.

\section{Author details}

'Department of Medical Oncology, Regina Elena National Cancer Institute,

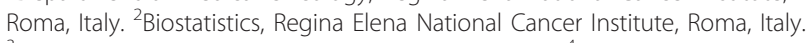
${ }^{3}$ Medical Oncology, Ospedale 'Belcolle', Viterbo, Italy. ${ }^{4}$ Clinical Oncology Unit, Istituto Neurotraumatologico Italiano (I.N.I.), Grottaferrata, Rome, Italy. ${ }^{5}$ Scientiphic Direction, Regina Elena National Cancer Institute, Roma, Italy. ${ }^{6}$ Medical Oncology, Ospedale San Donato, Arezzo, Italy.

\section{Competing interests}

None of the authors have competing interests or potential conflicts with this work. In particular:

- In the past five years have you received reimbursements, fees, funding, or salary from an organization that may in any way gain or lose financially from the publication of this manuscript, either now or in the future? NO

- Do you hold any stocks or shares in an organization that may in any way gain or lose financially from the publication of this manuscript, either now or in the future? NO

- Do you hold or are you currently applying for any patents relating to the content of the manuscript? Have you received reimbursements, fees,

funding, or salary from an organization that holds or has applied for patents relating to the content of the manuscript? NO

- Do you have any other financial competing interests? NO

Received: 10 January 2010 Accepted: 9 December 2010

Published: 9 December 2010

\section{References}

1. Sharifi N, Gulley JL, Dahut WL: Androgen deprivation therapy for prostate cancer. Jama 2005, 294:238-244.

2. Bolla M, Collette L, Blank L, Warde P, Dubois JB, Mirimanoff RO, Storme G, Bernier J, Kuten A, Sternberg C, et al: Long-term results with immediate androgen suppression and external irradiation in patients with locally advanced prostate cancer (an EORTC study): a phase III randomised trial. Lancet 2002, 360:103-106.

3. Bolla M, van Tienhoven G, de Reijke TM, van den Bergh AC, van der Meijden AP, Poortmans PM, Gez E, Kil P, Pierart M, Collette L, Groups EROaG-UT: Concomitant and adjuvant androgen deprivation (ADT) with external beam irradiation (RT) for locally advanced prostate cancer: 6 months versus 3 years ADT-Results of the randomized EORTC Phase III trial 22961. J Clin Oncol (Meeting Abstracts) 2007, 25:5014-.

4. D'Amico AV, Chen MH, Renshaw AA, Loffredo M, Kantoff PW: Androgen suppression and radiation vs radiation alone for prostate cancer: a randomized trial. Jama 2008, 299:289-295.

5. D'Amico AV, Manola J, Loffredo M, Renshaw AA, DellaCroce A, Kantoff PW: 6-month androgen suppression plus radiation therapy vs radiation therapy alone for patients with clinically localized prostate cancer: a randomized controlled trial. Jama 2004, 292:821-827.

6. Denham JW, Steigler A, Lamb DS, Joseph D, Mameghan H, Turner S, Matthews J, Franklin I, Atkinson C, North J, et al: Short-term androgen deprivation and radiotherapy for locally advanced prostate cancer: results from the Trans-Tasman Radiation Oncology Group 96.01 randomised controlled trial. Lancet Oncol 2005, 6:841-850.

7. Laverdiere J, Nabid A, De Bedoya LD, Ebacher A, Fortin A, Wang CS, Harel F: The efficacy and sequencing of a short course of androgen suppression on freedom from biochemical failure when administered with radiation therapy for T2-T3 prostate cancer. J Urol 2004, 171:1137-1140.

8. Pilepich MV, Winter K, John MJ, Mesic JB, Sause W, Rubin P, Lawton C Machtay M, Grignon D: Phase III radiation therapy oncology group (RTOG) trial 86-10 of androgen deprivation adjuvant to definitive radiotherapy in locally advanced carcinoma of the prostate. Int J Radiat Oncol Biol Phys 2001, 50:1243-1252.

9. Pilepich MV, Winter K, Lawton CA, Krisch RE, Wolkov HB, Movsas B, Hug EB, Asbell SO, Grignon D: Androgen suppression adjuvant to definitive 
radiotherapy in prostate carcinoma-long-term results of phase III RTOG 85-31. Int J Radiat Oncol Biol Phys 2005, 61:1285-1290.

10. Roach M, Bae K, Speight J, Wolkov HB, Rubin P, Lee RJ, Lawton C, Valicenti $R$, Grignon D, Pilepich MV: Short-term neoadjuvant androgen deprivation therapy and external-beam radiotherapy for locally advanced prostate cancer: long-term results of RTOG 8610. J Clin Oncol 2008, 26:585-591.

11. See WA, Tyrrell CJ: The addition of bicalutamide $150 \mathrm{mg}$ to radiotherapy significantly improves overall survival in men with locally advanced prostate cancer. J Cancer Res Clin Oncol 2006, 132(Suppl 1):S7-16.

12. Bria E, Cuppone F, Giannarelli D, Milella M, Ruggeri EM, Sperduti I, Pinnaro P, Terzoli E, Cognetti F, Carlini P: Does hormone treatment added to radiotherapy improve outcome in locally advanced prostate cancer?: meta-analysis of randomized trials. Cancer 2009, 115:3446-3456.

13. Roach M, Lu J, Pilepich MV, Asbell SO, Mohiuddin M, Terry R, Grignon D, Lawton C, Shipley W, Cox J: Predicting long-term survival, and the need for hormonal therapy: a meta-analysis of RTOG prostate cancer trials. Int J Radiat Oncol Biol Phys 2000, 47:617-627.

14. Braga-Basaria M, Dobs AS, Muller DC, Carducci MA, John M, Egan J, Basaria S: Metabolic syndrome in men with prostate cancer undergoing long-term androgen-deprivation therapy. J Clin Oncol 2006, 24:3979-3983.

15. Shahinian VB, Kuo YF, Freeman JL, Goodwin JS: Risk of fracture after androgen deprivation for prostate cancer. N Engl I Med 2005, 352:154-164.

16. Mohler J, Bahnson RR, Boston B, Busby JE, D'Amico A, Eastham JA, Enke CA, George D, Horwitz EM, Huben RP, et al: NCCN clinical practice guidelines in oncology: prostate cancer. J Natl Compr Canc Netw 8:162-200

17. Mohler JL: The 2010 NCCN clinical practice guidelines in oncology on prostate cancer. J Natl Compr Canc Netw 8:145.

18. Goldenberg SL, Klotz LH, Srigley J, Jewett MA, Mador D, Fradet Y, Barkin J, Chin J, Paquin JM, Bullock MJ, Laplante S: Randomized, prospective, controlled study comparing radical prostatectomy alone and neoadjuvant androgen withdrawal in the treatment of localized prostate cancer. Canadian Urologic Oncology Group. J Urol 1996, 156:873-877.

19. Soloway MS, Sharifi R, Wajsman Z, McLeod D, Wood DP, Puras-Baez A: Randomized prospective study comparing radical prostatectomy alone versus radical prostatectomy preceded by androgen blockade in clinical stage B2 (T2bNxM0) prostate cancer. The Lupron Depot Neoadjuvant Prostate Cancer Study Group. J Urol 1995, 154:424-428.

20. Pignon JP, Hill C: Meta-analyses of randomised clinical trials in oncology. Lancet Oncol 2001, 2:475-482

21. Bria E, Milella M, Gelibter A, Cuppone F, Pino MS, Ruggeri EM, Carlini P, Nistico C, Terzoli E, Cognetti F, Giannarelli D: Gemcitabine-based combinations for inoperable pancreatic cancer: Have we made real progress?: a meta-analysis of 20 phase 3 trials. Cancer 2007, 110:525-533.

22. Higgins JPT, Green S: Cochrane handbook for Systematic Reviews of intervention 4.2.6 [updated sep 2006]. The Cochrane Library Chichester, UK: John Wiley \& Sons, Ltd; 2006, 4.

23. Case LD, Kimmick G, Paskett ED, Lohman K, Tucker R: Interpreting measures of treatment effect in cancer clinical trials. Oncologist 2002, 7:181-187.

24. Borenstein M, Hedges LV, Higgins JPT, Rothstein HR: Introduction to MetaAnalysis Chichester, West Sussex, UK: John Wiley \& Sons, Ltd. Publication; 2009.

25. DerSimonian R, Laird N: Meta-analysis in clinical trials. Control Clin Trials 1986, 7:177-188

26. Shuster JJ: Empirical vs natural weighting in random effects metaanalysis. Stat Med 29:1259-1265.

27. Cochran WG: The combination of estimates from different experiments. Biometrics 1954, 10:101-129.

28. Deeks JJ: Issues in the selection of a summary statistic for meta-analysis of clinical trials with binary outcomes. Stat Med 2002, 21:1575-1600.

29. Huedo-Medina TB, Sanchez-Meca J, Marin-Martinez F, Botella J: Assessing heterogeneity in meta-analysis: Q statistic or 12 index? Psychol Methods 2006, 11:193-206.

30. Bria E, Gralla RJ, Raftopoulos H, Cuppone F, Milella M, Sperduti I, Carlini P, Terzoli E, Cognetti F, Giannarelli D: Magnitude of benefit of adjuvant chemotherapy for non-small cell lung cancer: meta-analysis of randomized clinical trials. Lung Cancer 2009, 63:50-57.
31. Parmar MKB, Machin D: Survival analysis: a practical approach Chichester (England): John Wiley; 1995.

32. Altman DG: Confidence intervals for the number needed to treat. Bm 1998, 317:1309-1312.

33. Bolla M, Collette L, Van Tienhoven G, Warde P, Dubois JB, Mirimanoff ROM, Storme G, Bernier J, Kuten A, Piérart M: Ten Year Results of Long Term Adjuvant Androgen Deprivation with Goserelin in Patients with Locally Advanced Prostate Cancer Treated with Radiotherapy: A Phase III EORTC Study. In International Journal of Radiation Oncology \& Biology \& Physics, American Society for Therapeutic Radiology and Oncology (ASTRO) 50th Annual Meeting September 1st, 2008; Boston Edited by: Elsevier 2008, S30-S31.

34. Bolla M, de Reijke TM, Van Tienhoven G, Van den Bergh AC, Oddens J, Poortmans PM, Gez E, Kil P, Akdas A, Soete G, et al: Duration of androgen suppression in the treatment of prostate cancer. N Engl J Med 2009, 360:2516-2527.

35. Crook J, Ludgate C, Malone S, Lim J, Perry G, Eapen L, Bowen J, Robertson S, Lockwood G: Report of a multicenter Canadian phase III randomized trial of 3 months vs. 8 months neoadjuvant androgen deprivation before standard-dose radiotherapy for clinically localized prostate cancer. Int I Radiat Oncol Biol Phys 2004, 60:15-23.

36. Horwitz EM, Bae K, Hanks GE, Porter A, Grignon DJ, Brereton HD, Venkatesan V, Lawton CA, Rosenthal SA, Sandler HM, Shipley WU: Ten-year follow-up of radiation therapy oncology group protocol 92-02: a phase III trial of the duration of elective androgen deprivation in locally advanced prostate cancer. J Clin Oncol 2008, 26:2497-2504.

37. Armstrong JG, Gillham CM, Dunne MT, Fitzpatrick DA, Finn MA, Cannon ME, Taylor JC, O'Shea CM, Buckney SJ, Thirion PG: A Randomized Trial (Irish Clinical Oncology Research Group 97-01) Comparing Short Versus Protracted Neoadjuvant Hormonal Therapy Before Radiotherapy for Localized Prostate Cancer. Int I Radiat Oncol Biol Phys.

38. Bria E, Cuppone F, Giannarelli D, Milella M, Ruggeri EM, Sperduti I, Pinnaro P, Terzoli E, Cognetti F, Carlini P: Does hormone treatment added to radiotherapy improve outcome in locally advanced prostate cancer?: meta-Analysis of Randomized Trials. Cancer 2009.

39. Crook J, Ludgate C, Malone S, Perry G, Eapen L, Bowen J, Robertson S, Lockwood G: Final report of multicenter Canadian Phase III randomized trial of 3 versus 8 months of neoadjuvant androgen deprivation therapy before conventional-dose radiotherapy for clinically localized prostate cancer. Int J Radiat Oncol Biol Phys 2009, 73:327-333.

40. Nanda A, Chen MH, Braccioforte MH, Moran BJ, D'Amico AV: Hormonal therapy use for prostate cancer and mortality in men with coronary artery disease-induced congestive heart failure or myocardial infarction. JAMA 2009, 302:866-873.

41. Dearnaley DP, Sydes MR, Graham JD, Aird EG, Bottomley D, Cowan RA, Huddart RA, Jose CC, Matthews JH, Millar J, et al: Escalated-dose versus standard-dose conformal radiotherapy in prostate cancer: first results from the MRC RT01 randomised controlled trial. Lancet Oncol 2007, 8:475-487

42. Kuban DA, Tucker SL, Dong L, Starkschall G, Huang EH, Cheung MR, Lee AK, Pollack A: Long-term results of the M. D. Anderson randomized doseescalation trial for prostate cancer. Int I Radiat Oncol Biol Phys 2008, 70:67-74.

43. Pollack A, Zagars GK, Starkschall G, Antolak JA, Lee JJ, Huang E, von Eschenbach AC, Kuban DA, Rosen I: Prostate cancer radiation dose response: results of the M. D. Anderson phase III randomized trial. Int $J$ Radiat Oncol Biol Phys 2002, 53:1097-1105.

44. Zietman AL, DeSilvio ML, Slater JD, Rossi CJ, Miller DW, Adams JA, Shipley WU: Comparison of conventional-dose vs high-dose conformal radiation therapy in clinically localized adenocarcinoma of the prostate: a randomized controlled trial. JAMA 2005, 294:1233-1239.

45. Souhami L, Bae K, Pilepich M, Sandler H: Impact of the duration of adjuvant hormonal therapy in patients with locally advanced prostate cancer treated with radiotherapy: a secondary analysis of RTOG 85-31. J Clin Oncol 2009, 27:2137-2143.

46. Alexander A, Crook J, Jones S, Malone S, Bowen J, Truong P, Pai H, Ludgate $C$ : Is biochemical response more important than duration of neoadjuvant hormone therapy before radiotherapy for clinically localized prostate cancer? An analysis of the 3-versus 8-month randomized trial. Int J Radiat Oncol Biol Phys 76:23-30. 


\section{Pre-publication history}

The pre-publication history for this paper can be accessed here: http://www.biomedcentral.com/1471-2407/10/675/prepub

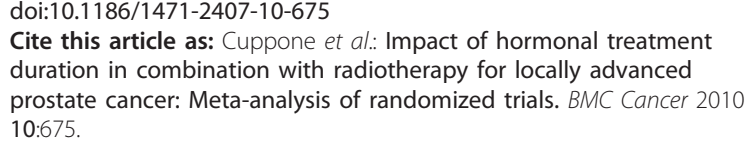

Submit your next manuscript to BioMed Central and take full advantage of:

- Convenient online submission

- Thorough peer review

- No space constraints or color figure charges

- Immediate publication on acceptance

- Inclusion in PubMed, CAS, Scopus and Google Scholar

- Research which is freely available for redistribution 